\title{
Failure to thrive or failure to rear?
}

\author{
M. J. O'CALLAGHAN AND D. HULL \\ From the Department of Child Health, University Hospital and Medical School, Clifton Boulevard, \\ Nottingham NG7 $2 U H$
}

SUMMARY The study group comprised 40 unselected Caucasian children admitted to hospital whose ages were between 3 months and 3 years and whose weights were $<3$ rd centile. A comparison group comprised 34 children from a similar background whose weights were between the 25th and 75th centiles. The mothers of all 74 children were interviewed and information was obtained on physical health of the child, social and family factors, bonding, feeding difficulties, and maternal childhood experience. In 23 of the 40 underweight children the organic disease was considered to be insufficient to explain the child being underweight and to be probably insufficient in a further 9 children. Three factors occurred more frequently in these 32 underweight children. The mother often perceived herself as having a disturbed mood and used the word 'depression' to describe these feelings. She also tended to come from a lower social class than the mother in the comparison group, and her infant frequently had a low birthweight. Identification of these children is not difficult; clinical investigations need to be minimal, and therapy should be directed towards supporting the mother emotionally, improving her relationship with her child, and increasing her mothering skills.

Failure to thrive is a term applied to a young child whose growth, particularly weight, is much less than anticipated. It is a syndrome with many causes. It is a common manifestation of ill health in the early years of life; on the other hand, it may equally be a consequence of inadequate parental care-whether due to parental ill health, ignorance, or poverty. Occasionally it is the primary health problem in the minds of the parents. Many organic diseases, from gluten enteropathy to chronic renal failure, present with 'failure to thrive' and in attempts to exclude these possibilities undernourished infants admitted to hospital are often subjected to many investigations, all of which will probably give negative results. However, these investigations may be considered to be essential before the more ill-defined and subtler factors can be evaluated and an appropriate approach adopted. The diagnostic approach has the disadvantage that it delays recognition of the real problems and it is expensive, but more important than either of these, it tends to confirm to the parents that there is a disorder in the infant which would come to light if only the doctor could make the appropriate investigation.

Clinical experience and community studies have shown the importance of nonorganic factors in

Received 7 December 1977 producing growth failure. Any health care programme or hospital policy evaluating underweight children admitted to hospital must assess all factors within the particular family and community.

In this report an attempt was made to evaluate maternal and social factors, mother-child bonding, and infant practices, as well as organic disturbances in a group of underweight children admitted to hospital. The report is mainly concerned with those children in whom no underlying organic disorder was present. As this group reflects what a hospital sees, it does not necessarily represent the range of problems in the community.

\section{Method}

During a 5-month period, 40 Caucasian children aged between 3 months and 3 years and weighing $<3$ rd centile on the Tanner Whitehouse Charts (1959) were admitted to the hospital (study group). As by definition 3 of every 100 children are $<3$ rd centile for weight, this group may have included normal children in addition to those failing to thrive. Another group of 34 unselected children of similar ages but whose weights were between the 25 th and 75 th centiles was also studied during the same period (comparison group). Only a single measurement was made, so linear growth was not assessed. The two 
groups were similar in age distribution. There were more boys than girls among the undersized children, but this difference was not statistically significant.

The study group was divided in 3 according to whether organic disease was considered responsible (group A, 8 children), possibly responsible (group B, 9 children), or not responsible (group C, 23 children) for the child being below weight. The nature of the organic disorder present in children in groups $A$ and $B$ is shown in Table 1. A profile of the ages, weights, and distribution of the 40 children in the study group is shown for boys in Fig. 1 and for girls in Fig. 2.

Although height was not a criterion for admission to the study, it was measured in $\mathbf{3 7}$ of the $\mathbf{4 0}$ children in the study group. Seven of 8 in group A, 5 of 9 in group B, and 10 of 20 children in group $C$ had
Table 1 Nature of organic disorder present in children in groups $A$ and $B$

\begin{tabular}{|c|c|}
\hline roup $A$ & $\begin{array}{l}\text { (organic explanation for being underweight }(n=8) \\
\text { Tracheo-oesophageal fistula with recurrent aspiration } \\
\text { Total anomalous pulmonary venous drainage } \\
\text { Pulmonary atresia } \\
\text { Severe mental retardation and cerebral palsy } \\
\text { Central nervous system degeneration } \\
\text { Hypothalamic tumour } \\
\text { Down's syndrome } \\
\text { Cystinosis }\end{array}$ \\
\hline & $\begin{array}{l}\text { (possible organic explanation for being underweight) }(n=9) \\
\text { Moderately severe asthma ( } 2 \text { cases) } \\
\text { Gastro-oesophageal reflux ( } 2 \text { cases) } \\
\text { Recurrent paroxysmal atrial tachycardia } \\
\text { Severe eczema } \\
\text { Urinary tract infection } \\
\text { Poor weight gain in hospital (2 cases) }\end{array}$ \\
\hline
\end{tabular}

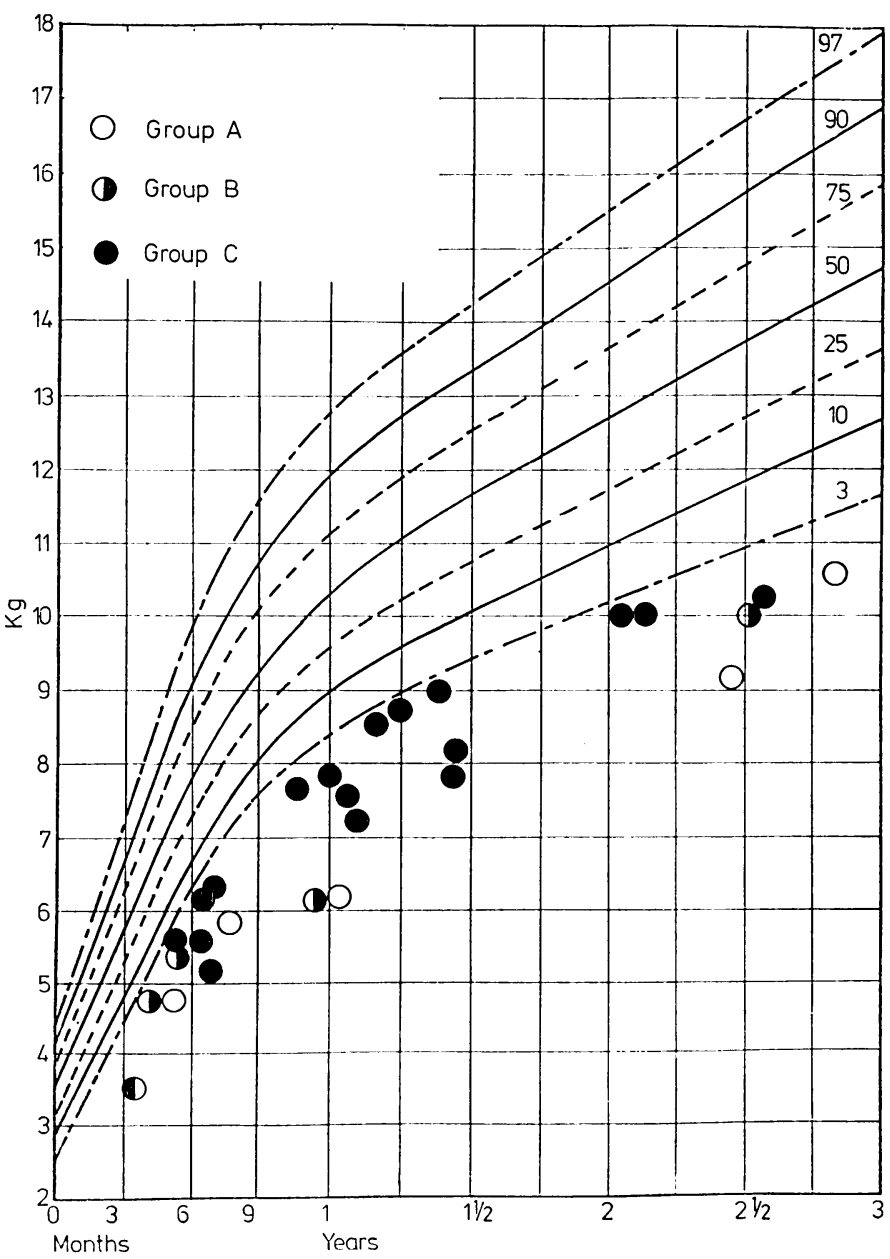

Fig. 1 Underweight boys in study group. 


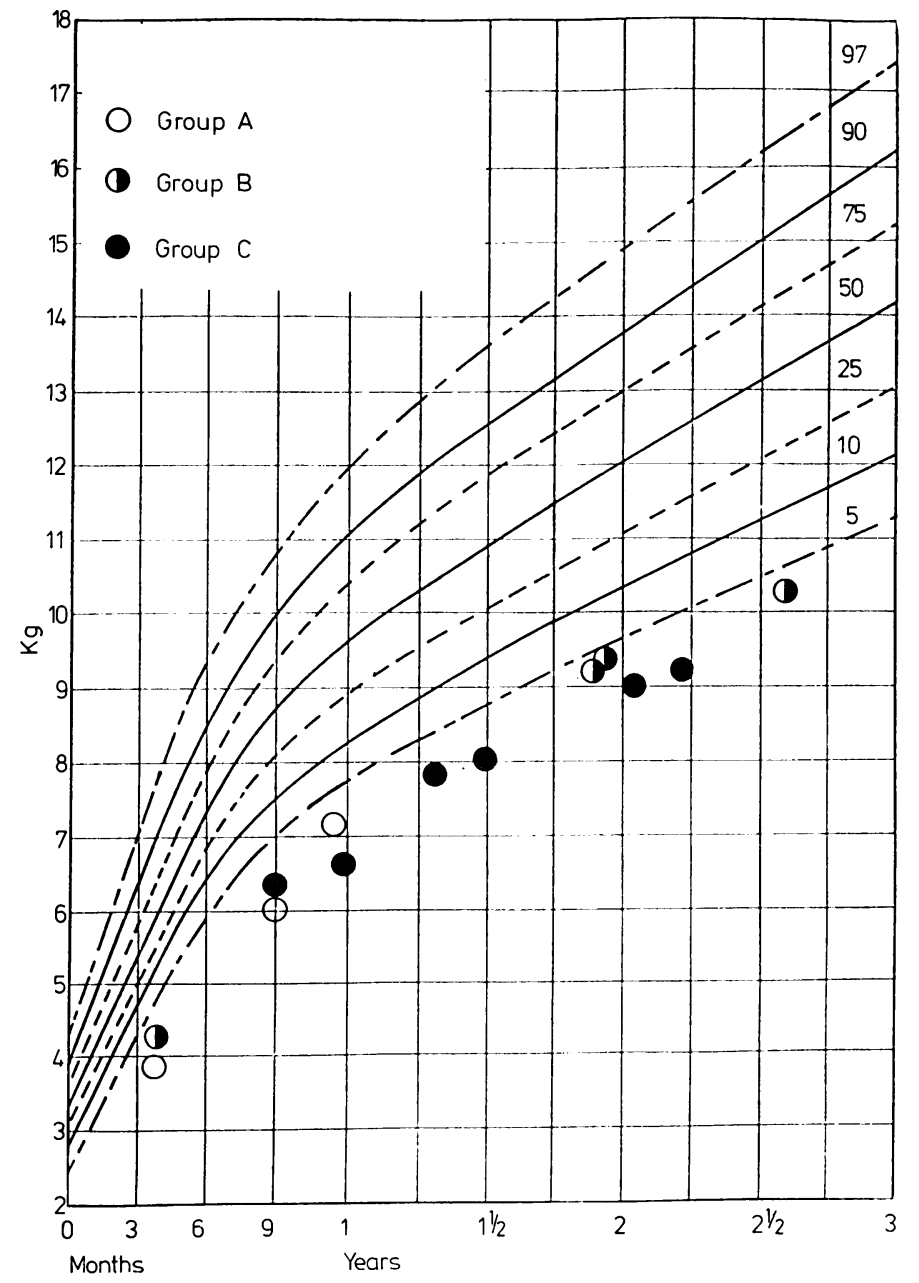

Fig. 2 Underweight girls in study group.

heights $<3$ rd centile. Thus, many of the children were short as well as underweight.

The nature of the interview was explained to all the mothers by the same person. The questionnaire was semistructured and designed to explore 5 areas: physical health of the child, social and family structure, the attachment process, feeding difficulties, and maternal childhood experience.

Physical health of the child, and social and family structure. Facts were sought on these.

Mother-infant attachment. Information was obtained on birthweight, gestation, type of delivery, difficulties in the pregnancy and neonatal period, and separation after birth. The mother rated how often the baby cried, how easy he was to comfort, and how soundly he slept. Maternal attitude towards the pregnancy and subsequent feelings of depression were explored. Each mother was told that it was common to feel depressed after the birth of a child and then asked if this had happened to her. Any mother in whom symptoms persisted for $>2$ weeks was regarded as showing postpartum depression. The mother was then asked if at any time after this she had become depressed and, if the answer was yes, had she sought help from her doctor.

Feeding difficulties. Each mother was asked about initial method of feeding and associated difficulties. She was also asked to grade her enjoyment of the feeding itself, the appetite of the child during the previous few months, and whether the child was a 'fussy' eater. 
Maternal childhood experience. Each mother was asked to rate the happiness of her own childhood and the quality of her relationship with her own mother. Details of any childhood separation were obtained.

\section{Results}

Results from group A (children in whom organic disease was considered responsible for their being underweight) have not been included as these results were generally similar to those of the comparison group.

Physical health. Most children were admitted with an acute intercurrent illness (Table 2). Only 3 of 23 children in group $\mathbf{C}$ had previously been identified as failing to thrive, but 10 had had previous hospital admissions. Six of the 34 in the comparison group had had previous admissions.

Six of the children in group $\mathbf{C}$ had never attended an infant welfare clinic compared with one child in the comparison group. The mode of admission was similar for groups B, C, and the comparison group.

Social and family structure. The social class distribution was determined from the father's occupation, or the mother's occupation if she was single, by referring to the Registrar General's Classification of Occupations for the 1970 census. In Table 3 social classes I and II, and IV and V are combined. Group C contained an excess of social classes IV and $\mathrm{V}$, but it and the comparison group were similar

Table 2 Nature of disorder precipitating admission

\begin{tabular}{llll}
\hline Precipitating disorder & $\begin{array}{l}\text { Comparison } \\
\text { group }\end{array}$ & $\begin{array}{l}\text { Study group } \\
(A, B, \text { and } C)\end{array}$ & $\begin{array}{l}\text { Group } C \\
\text { only }\end{array}$ \\
\hline Acute lower respiratory & 17 & 11 & 7 \\
$\quad$ illness & 17 & 5 & 4 \\
Febrile convulsion & 9 & 6 & 3 \\
Fever of undetermined & 2 & 3 & 2 \\
$\quad$ cause & 2 & 6 & 3 \\
$\begin{array}{l}\text { Gastrointestinal symptoms } \\
\text { Otitis media }\end{array}$ & - & 3 & 3 \\
Failure to thrive for & - & 6 & 1 \\
$\quad$ investigation & 4 & 40 & 23 \\
Others & 34 & 4 & \\
No. of children & & & \\
\hline
\end{tabular}

Table 3 Social class distribution of mothers

\begin{tabular}{lllll}
\hline Social class & $\begin{array}{l}\text { Comparison } \\
\text { group } \\
(n=34)\end{array}$ & $\begin{array}{l}\text { Study group } \\
(n=40)\end{array}$ & $\begin{array}{l}\text { Group } B \\
(n=9)\end{array}$ & $\begin{array}{l}\text { Group } C \\
(n=23)\end{array}$ \\
\hline I and II & 6 & 2 & 0 & 0 \\
III & 20 & 22 & 4 & 12 \\
IV and V & 4 & 11 & 4 & 7 \\
\hline
\end{tabular}

Mothers not included were either single and unemployed, or had husbands in the services. in terms of maternal age, paternal age, midparental height, number of children in the family, birth order of the index child, and birth interval to the next eldest child. The two groups were also comparable in the number of mothers having employment outside the home, the number who were single or separated, and the number coming from areas of the city identified as showing high socioeconomic deprivation in a County Council Draft Report Survey (1974).

Attachment. The nature of the delivery was generally similar between the groups, except that 3 babies in group $\mathrm{C}$ had been born by caesarean section compared with none in the comparison group. There were no differences between the groups as to when the mothers had first seen or handled their babies, apart from the mothers who had had a caesarean section.

The study group contained more babies born both prematurely and light-for-dates. Five of 23 in group $\mathrm{C}$ and one of 9 in group B had a gestation $<37$ weeks compared with one in 34 in the comparison group. Four of the 5 premature children in group $\mathrm{C}$ remained $<3$ rd centile for weight at the time of the study, making an allowance for gestation. Of the babies born at or after 37 weeks of gestation, 4 of 23 in group C and one of 9 in group B had a birthweight $<2500 \mathrm{~g}$ compared with none in the comparison group. The differences in birthweight between group $\mathbf{C}$ and the comparison group for babies born at 37 weeks of gestation remained highly significant if only children of social class III mothers were compared $(\mathrm{P}<0.003$, Mann Whitney $U$ test).

No significant differences existed between the groups in the mother's rating of how frequently the baby cried, how easy he was to comfort, or how soundly he slept. There was a trend for mothers in group $\mathbf{C}$ to be less happy than other mothers about becoming pregnant, although in all groups mothers appeared from the beginning of the pregnancy to want to keep the babies. More mothers in group C than in the comparison group regarded themselves as unwell during the pregnancy, although this difference was less pronounced if only social class III mothers were compared.

A marked difference existed between the groups in the number of mothers who experienced significant postpartum depression, who subsequently felt they were depressed, and who visited their doctor because they considered themselves depressed. These differences, shown in Table 4, remain highly significant if only social class III mothers are considered. All differences between the comparison mothers and group $\mathbf{C}$ were significant at $\mathbf{P}<0.01$, except for postpartum depression where $P$ was $<0.05$ ( $\chi^{2}$ and Fisher's exact probability tests). 
Table 4 Mothers in comparison group, group B, or group $C$ with 'depression' either in the postpartum period or subsequently

\begin{tabular}{lllll}
\hline Group & \multicolumn{2}{l}{ No. of mothers } & \\
\cline { 2 - 5 } & In group & $\begin{array}{l}\text { With signifi- } \\
\text { cant post- } \\
\text { partum } \\
\text { depression }\end{array}$ & $\begin{array}{l}\text { With depres- } \\
\text { sion after } \\
\text { puerperium }\end{array}$ & $\begin{array}{l}\text { Who visited } \\
\text { GP for } \\
\text { depression } \\
\text { afier } \\
\text { puerperium }\end{array}$ \\
\hline Comparison & 34 & 4 & 8 & $\begin{array}{l}3 \text { (1 in social } \\
\text { class III) } \\
\text { (2 in social } \\
\text { class III) } \\
10 \text { (6 in social } \\
\text { class III) }\end{array}$ \\
\hline
\end{tabular}

Feeding difficulties. A difference between group $\mathbf{C}$ and the comparison group in intention to breast feed $(\mathrm{P}<\mathbf{0} \cdot \mathbf{1})$ became less apparent if only social class III mothers were compared. Mothers in groups B and $\mathrm{C}$ tended to regard their babies initially as being difficult to feed, and to associate mixed feelings with the feeding itself. There were no significant differences between group $\mathbf{C}$ and the comparison group on whether the child's appetite before the current admission was regarded by the mother as good, average, or poor, nor on whether the child was considered a 'fussy' eater or not. Only 5 of the children in group $\mathbf{C}$ were described as having a poor appetite.

Maternal childhood experience. Six of $\mathbf{2 3}$ mothers in group C, and $\mathbf{5}$ of $\mathbf{3 4}$ from the comparison group had a protracted family disruption, not due to parental death, before they were 12. Three mothers in the comparison group and 3 in group $C$ had spent a period either fostered or in a children's home.

Mothers in each group had a similar number of siblings, Four mothers in the comparison group and 2 in group $\mathbf{C}$ described their own childhoods as sad or very sad, while 3 of the comparison group and 6 of group $\mathbf{C}$ regarded their relationships with their own mothers as poor or very poor.

\section{Discussion}

Three factors were more common in the underweight child admitted to hospital: the mother of the child often perceived herself as having a disturbance of mood, her social class tended to be lower than that of the mother in the comparison group, and her infant frequently had a low birthweight. These 3 factors are not necessarily in themselves causal, but together with the trend for differences in other areas they indicate a complex interaction between the mother, the child, and the environment. While differences in social class and birthweight were expected, the magnitude of the association between mood disturbance in the mother and the child being underweight was surprising.

Although these mothers used the word 'depression' to describe their disturbed mood, it was not established whether it was pure depression or a depression associated with an underlying character or neurotic disorder. Neligan et al. (1976) noted an increased incidence of neuroticism and rejection in mothers of light-for-date infants. Fischhoff et al. (1971) and Hutton and Oates (1977) have described the presence of depression and character disorder in mothers of infants with nonorganic growth failure. Nine of 16 mothers reported by Fischhoff et al. (1971) showed evidence of depression, and in 7 cases this was thought to be associated with a character disorder. The relationship between these depressive feelings, the child, and the child being underweight is not clear. No information is available on the frequency of depressive symptoms in the mothers before they became pregnant. All 5 of our mothers who were unhappy to be pregnant complained of subsequent depression and 4 had sought help from their doctors. Four of the 7 mothers with premature infants had also seen their doctors because of depression.

As the study and comparison groups were selected on the basis of weight, the lower birthweight in the study group children is perhaps not surprising. Although the 2 groups were similar in terms of maternal age, height, and parity, no information was available about smoking habits of the mothers. The mothers of infants who were born light-for-dates or premature were no different from other mothers of underweight children in their responses to the questionnaire. Social class is related to birthweight (Chamberlain, 1975) and to the subsequent growth pattern of the child (Miller et al., 1960). As an indication of subsequent growth of the child, Neligan and Prudham (1976) found that a variety of family factors, the most significant of which was the quality of mothering in the first 3 years, were more valid indicators than was social class itself. Low birthweight, particularly $<5$ th centile for gestational age, is associated with subsequent behavioural disturbance, diminished growth, and reduced intellectual abilities of the child (Neligan et al., 1976). The average birthweight of children in group $\mathrm{C}$ whose gestation was $>37$ weeks was however $>10$ th centile.

Whitten et al. (1969)" showed that children with failure to thrive often have inadequate nutrition despite the mother giving a history of an apparently normal intake. Inadequate nutrition is probably present as one aspect of a more general inadequacy of mothering in those underweight children in group C. 
Frommer and O'Shea (1973) stated that the difficulty a mother experiences with her child is related to her own mothering experience, particularly to separation from her parents at an early age. In this study the mothers of the underweight children had no greater incidence of childhood family disruption or separation.

That no difference existed in the number of children coming from inner city areas was surprising in view of the known high incidence in this locality of 'light-for-dates' infants and cot deaths (Madeley, 1977). Boys have been recognised as being particularly vulnerable in this neonatal period and first few years of life and, if the study had been larger, the preponderance of boys in group $\mathrm{C}$ might have been significant.

Low birthweight has been identified in both Sheffield (Emery, 1976) and Nottingham (Madeley, 1977) as a risk factor for sudden infant death, a syndrome which is itself associated with social disadvantage. Similarities also exist between the syndromes of nonaccidental injury and failure to thrive (Lynch, 1977). A severely disturbed parentinfant attachment has been suggested as the basis of both syndromes (Klaus and Kennell, 1976). No instances of nonaccidental injury were recognised in these 40 children at the time.

Plotting of all children admitted to hospital or attending infant welfare clinics on centile charts would identify the child with poor growth. A social and parental history would suggest whether the child was underweight because of nonorganic factors, and what the major factors operating in that child were. While a 2-week period in hospital to confirm the diagnosis by assessing weight gain is useful, it is not always practicable or desirable. Whether the child is identified in its own right, or whether the mother identifies the child when she presents because of a mood disturbance complaining of depression, there is an argument for early supportive intervention to encourage optimal growth and development.

Both behavioural disturbances (Pollitt and Eichler, 1976) and reduced intelligence (Hutton and Oates, 1977) have been documented in children in circumstances where growth failure is associated with a disturbed parent-infant attachment. There is inadequate information to comment on the development and behaviour of children in this study, but a danger would exist in extrapolating findings from other studies where a variety of criteria have been used to identify children with failure to thrive.

Treatment should aim to support the mother emotionally, improve her relationship with her child, and increase her mothering skills. If a warm relationship is established with the mother, it may be possible to influence her by counselling, particularly in play situations with the child. A health visitor attached to both a general practitioner and infant welfare clinic and concerned with the welfare of children in a particular area, would seem the most suitable person to undertake this task.

We thank Dr P. Barbor, Dr D. Johnston, and Dr A. Milner for allowing study of their patients.

\section{References}

Chamberlain, R. (1975). British Births, 1970: The First Week of Life, volume 1. Heinemann Medical: London.

Emery, J. L. (1976). Unexpected death in infancy. In Recent Advances in Paediatrics, volume 5, p. 203. Edited by D. Hull. Churchill Livingstone: London.

Fischhoff, J., Whitten, C. F., and Pettit, M. G. (1971). A psychiatric study of mothers of infants with growth failure secondary to maternal deprivation. Journal of Pediatrics, 79, 209-215.

Frommer, E. A., and O'Shea, G. O. (1973). The importance of childhood experience in relation to problems of marriage and family building. British Journal of Psychiatry, 123, 157-160.

Hutton, I. W., and Oates, R. K. (1977). Non organic failure to thrive: a long-term follow-up. Pediatrics, 59, 73-77.

Klaus, M. H., and Kennell, J. H. (1976). Parent to infant attachment. In Recent Advances in Paediatrics, volume 5, p. 129. Edited by D. Hull. Churchill Livingstone: London.

Lynch, M. (1977). International congress on child abuse and neglect. Developmental Medicine and Child Neurology, 19, 265-267.

Madeley, R. J. (1977). Social factors associated with post neonatal death in Nottingham 1974-1976 (abstract). Archives of Disease in Childhood, 52, 809.

Miller, F. J. W., Court, S. D. M., Walton, F. S., and Knox, E. G. (1960). Growing up in Newcastle upon Tyne, p. 147. Oxford University Press: London.

Neligan, G. A., Kolvin, I., Scott, D. Mc. I., and Garside, R. (1976). Born too Soon or Born too Small. Clinics in Developmental Medicine No. 61. Heinemann Medical: London.

Neligan, G. A., and Prudham, D. (1976). Family factors affecting child development. Archives of Disease in Childhood, 51, 853-858.

Pollitt, E., and Eichler, A. (1976). Behaviour disturbance among failure to thrive children. American Journal of Diseases of Children, 130, 24-29.

Whitten, C. F., Pettit, M. G., and Fischhoff, J. (1969). Evidence that growth failure from maternal deprivation is secondary to undereating. Journal of the American Medical Association, 209, 1675-1682.

Correspondence to Dr M. J. O'Callaghan, Department of Child Health, Medical School, Queen's Medical Centre, Nottingham NG7 2UH. 